\title{
(Mg Rich Primer-Powder Topcoat) coating system for the corrosion protection of Al alloys
}

\author{
Junren Lin ${ }^{*}$, Casey Orgon ${ }^{\S}$, Dante Battocchi ${ }^{\S}$, Gordon P. Bierwagen ${ }^{\S}$ \\ Department of Coatings and Polymeric Materials, North Dakota State University \\ 1735 NDSU Research Park Drive, Fargo, ND 58102, USA
}

\begin{abstract}
(Mg rich primer-powder topcoat) coating system was first developed and characterized in this research for the corrosion protection of $\mathrm{Al}$ alloys. Feasibility of using $\mathrm{Mg}$ rich primer (MgRP) as an under layer for powder topcoat was proved through evaluating thermal stability of MgRP, adhesion strength of the (MgRP-powder topcoat) coating systems, and cross-section images of the coating systems. In addition, corrosion protection effects of (MgRP-powder topcoat) coating system were evaluated by exposing samples to accelerated weathering test. Electrochemical impedance spectroscopy (EIS) and visual inspection were conducted during exposure. The results show that (MgRP-powder topcoat) coating systems provided much longer corrosion protection time to $\mathrm{Al}$ substrate than the powder topcoat alone. Moreover, gloss measurements indicated that for the coating systems tested in this research, using MgRP as an under layer does not affect the final coating appearance.
\end{abstract}

Key Words: Mg rich primer; powder topcoat; corrosion protection

\footnotetext{
* Corresponding author. E-mail address: Junren.Lin@ndsu.edu

$\S$ Department of Coatings and Polymeric Materials, North Dakota State University, 1735 NDSU Research Park Drive, Fargo, ND 58102, USA
} 


\section{Introduction}

Aluminum alloys are widely used in engineering structures and components due to their light weight and excellent mechanical properties[1,2]. However, the alloying elements which contribute to the good mechanical properties also make the alloy prone to localized corrosion[3,4]. One of the most common and economic approaches to protect Al alloys from corrosion is to apply coatings as protective layers. For example, powder coatings and magnesium-rich primers (MgRPs) are both widely used for the corrosion protection of Al alloys[5-8]. These two coating systems both have advantages and limitations: powder coatings designed for corrosion protection usually provide very good barrier properties and long lifetime[9]. However, powder coatings by themselves lack corrosion inhibition effect and do not perform well once a defect has developed in the coatings[10,11]. MgRPs can provide effective cathodic protection to $\mathrm{Al}$ alloys[12,13]. However, since MgRPs are formulated at high pigment volume concentration (PVC) to ensure cathodic protection, they show insufficient barrier properties and require a topcoat to realize good performance[14,15].

Therefore, this research proposed a (MgRP-powder topcoat) coating system on the premise that the combination of the cathodic protection effect from MgRPs and the barrier protection from powder topcoat will achieve superior corrosion protection effect. Furthermore, MgRPs are formulated at high PVC, so they might provide desired conductivity for electrostatic spray application, which is the most common application method for powder coating.

To evaluate the corrosion protection effect of (MgRP-powder topcoat) coating system, samples were exposed to accelerated weathering test, and characterized by electrochemical impedance spectroscopy (EIS) and visual inspection. Thermal stability of MgRP, adhesion strength of the 
(MgRP-powder topcoat) coating system, and gloss change of powder topcoat were also studied in this research.

\section{Experimental}

\subsection{Samples preparation}

The AA2024-T3 panels used in this study were purchased from Q-Lab ${ }^{\dagger}$. The glass panels were purchased from VWR International ${ }^{\dagger}$. The epoxy resin system used was a two component system (Epon 828 and Epikure 3164) purchased from Hexion Inc ${ }^{\dagger}$. BYK 346, from BYK-chemi ${ }^{\dagger}$, was used as dispersant, tert-butyl acetate (from TCI American ${ }^{\dagger}$ ) and p-xylene (from Sunnyside Corporation $^{\dagger}$ ) were the solvents used. The Mg pigment was supplied by READE Advanced Materials ${ }^{\dagger}$. The powder coat was a polyester based powder coating with b-hydroxyalkylamide (b-HA) as the crosslinker provided by Valspar Corporation ${ }^{\dagger}$.

The AA2024-T3 panels were sand blasted with $\mathrm{Al}_{2} \mathrm{O}_{3}$ grit to remove the oxide layer, grease and oils. The panels were then cleaned with Prekote ${ }^{\dagger}$, washed with DI water and dried with paper towel. Mg rich primer was air sprayed onto AA2024-T3 panels and cured at room temperature for seven days before applying powder topcoat. The thickness of MgRP was $40 \pm 10 \mu \mathrm{m}$ as measured by a digital thickness gauge elcometer $345^{\dagger}$. Powder coat was applied on top of MgRP by electrostatic spray and dip methods. For both application methods, the MgRP coated panels were first preheated at $350^{\circ} \mathrm{F}$ for 20 mins, and then removed from the oven for application. For electrostatic method, a Nordson Versa-Spray II electrostatic spray system was used. Panels were sprayed while suspended by metal hangers in a steel faraday cage grounded to the electrostatic spray unit. Air pressures and electrical settings for the spray unit were $12 \mathrm{psi}$ for the fluidizing air, 15 psi for the powder supply air, 10 psi for the atomization air, and an $80 \mathrm{kV}$ applied voltage potential. After electrostatic spray, the panels were cured at $350^{\circ} \mathrm{F}$ for $10 \mathrm{mins}$.

\footnotetext{
${ }^{\dagger}$ Trade name
} 
For dip method, powder topcoats were applied by fully immersing the preheated panels into the fluidized powder for approximately two seconds to build proper film thickness. The coated panels were then removed from the fluidized bed hopper and cured in the oven at $350^{\circ} \mathrm{F}$ for 10minutes. After curing, panels were removed from the oven and immediately quenched in a water bath. The coating systems tested in this research and their corresponding thickness are summarized in Table1. Free films were prepared by air spraying MgRP on Al panels covered with Mylar®, which has very low surface tension, easing peeling off of the primer.

\section{Table 1}

Coating Systems Tested in This Research and Their Thickness

\begin{tabular}{ccc}
\hline Abbreviation & Coating systems & Thickness $(\mu \mathrm{m})$ \\
\hline Al-E & Powder coat on bare Al substrate by electrostatic spray & $110 \pm 10$ \\
Al-D & Powder coat on bare Al substrate by fluidized bed & $170 \pm 10$ \\
MgRP-E & Powder coat on MgRP coated Al substrate by electrostatic & $160 \pm 10$ (total) \\
MgRP-D & Powder coat on MgRP coated Al substrate by fluidized bed & $170 \pm 10$ (total) \\
\hline
\end{tabular}

\subsection{Scanning electron microscope}

For scanning electron microscope (SEM) investigations, sample cross sections were mounted in MetLab ${ }^{\dagger}$ Jet-Set two part epoxy. After curing, each sample was polished using 800, 1000, and 1200 grit sandpaper. Fine polishing was carried out using $3 \mu \mathrm{m}$, and $1 \mu \mathrm{m}$ diamond paste followed by $0.05 \mu \mathrm{m} \mathrm{Al}_{2} \mathrm{O}_{3}$ on text-met 2500 pads until a mirror finish was achieved. Then samples were coated with gold using a Hummer II sputter coater ${ }^{\dagger}$. Images of the cross-section were taken using a JEOL JSM-6490LV scanning electron microscope (from JEOL Ltd ${ }^{\dagger}$ ) in back scattering mode with $15 \mathrm{KeV}$ acceleration voltage.

\subsection{Thermal and adhesion Measurements}


Thermogravimetric analysis (TGA) was conducted using a TA Instruments $^{\dagger}$ Q500 Thermogravimetric Analyzer on three samples: $40 \% \mathrm{Mg}$ rich primer, the same epoxy primer without $\mathrm{Mg}$ pigment, and $\mathrm{Mg}$ pigment. All samples were heated in air from $25^{\circ} \mathrm{C}$ to $300^{\circ} \mathrm{C}$ at a rate of $10^{\circ} \mathrm{C} / \mathrm{min}$. Differential scanning calorimetry (DSC) analysis was conducted using a TA Instruments Q1000 series DSC. The testing method used was a heat-cool-heat cycle. The samples were first equilibrated at $-75^{\circ} \mathrm{C}$ and then subjected to a heat cycle at the rate of $10^{\circ} \mathrm{C} /$ min to $200^{\circ} \mathrm{C}$, followed by cooling to $-75^{\circ} \mathrm{C}$ and held isothermally for 5 minutes, and a final heating cycle at a rate of $10^{\circ} \mathrm{C} / \mathrm{min}$ to $250^{\circ} \mathrm{C}$. Pull-off adhesion test was conducted on (MgRP-powder topcoat) coating system using Positest ${ }^{\circledR}$ pull-off adhesion tester ${ }^{\dagger}$ according to ASTM D4541-09. Loctite 907 Hysol was used for mounting dollies. Five sets of measurements were made on each sample. The dolly used for the test has a diameter of $20 \mathrm{~mm}$ and the pull off rate is $1.00 \mathrm{MPa} / \mathrm{s}$.

\subsection{Accelerated weathering test}

Following ASTM standard G85-11 (Prohesion ${ }^{\circledR}$ test), powder coated panels (both scribed and unscribed) were placed into a Q-fog cyclic corrosion tester ${ }^{\dagger}$. The back and the edges of panels were covered with tape. The solution for Prohesion ${ }^{\circledR}$ procedure is Dilute Harrison's Solution (DHS), which consists of $0.05 \% \mathrm{NaCl}$ and $0.35 \%\left(\mathrm{NH}_{4}\right)_{2} \mathrm{SO}_{4}$. Each cycle includes one hour salt fog cycle at $25^{\circ} \mathrm{C}$ and one hour dry air purge cycle at $35^{\circ} \mathrm{C}$. The panels were removed from the tester periodically for visual analysis, gloss measurement and electrochemical impedance spectroscopy test. All panels were removed at the end of fog cycle. At least 3 panels were tested for each sample.

\subsection{Visual inspection and gloss measurement}


The images of the panels were taken by Nikon D3000 digital camera. The light source was above the unexposed panels and to the side of the exposed panels. The position of the light source was changed for exposed panels because the side position of the light cast more visible shadows that make the coating delamination easier to see. Gloss $\left(60^{\circ}\right)$ was measured using Rhopoint IQ Glossmeter \& Goniophotometer ${ }^{\dagger}$. Nine sets of measurements were made on each sample

\subsection{EIS measurement}

EIS measurements were performed using a Gamry Reference 600 potentiostat $^{\dagger}$ (open lead impedance exceed $10 \mathrm{~T} \Omega$ at $0.01 \mathrm{~Hz}$ ) with three-electrode setup: a test panel was used as working electrode, a saturated calomel electrode (SCE) was used as reference electrode, and a Pt mesh was used as counter electrode. The exposed area of the working electrode was $7.06 \mathrm{~cm}^{2}$. The testing electrolyte was DHS. Impedance spectra were collected at the open circuit potential, through a frequency range from $100 \mathrm{kHz}$ to $0.01 \mathrm{~Hz}$ with $10 \mathrm{mV}$ alternating current (AC) voltage applied.

\section{Results and discussion}

\subsection{Thermal stability of $M g R P s$}

Since powder topcoat application includes preheat and curing samples at $350^{\circ} \mathrm{F}\left(177^{\circ} \mathrm{C}\right)$, thermogravimetric analysis (TGA) was conducted to observe if MgRP can endure the high temperature. The results (Fig.1) show that MgRP lost only about $1 \%$ weight at $350^{\circ} \mathrm{F}$. To determine the cause of the weight loss from MgRP, TGA was conducted on Mg pigment and epoxy primer without $\mathrm{Mg}$ pigment. The results show that $\mathrm{Mg}$ pigment didn't undergo any weight loss at $350^{\circ} \mathrm{F}$, but epoxy primer lost about $4 \%$ weight at the temperature. It is known that when a 
coating is cured below glass transition temperature $\left(\mathrm{T}_{\mathrm{g}}\right)$, residual solvent remains in the coating for years after the coating has formed[16]. $\mathrm{T}_{\mathrm{g}}$ of the $\mathrm{MgRP}$ was $36.24^{\circ} \mathrm{C}$ as measured by DSC (Fig. 2), which is higher than the curing temperature of MgRP (room temperature). Therefore, it is very likely that the weight loss is from unevaporated solvents. Generally, $10 \%$ of weight loss is considered as the threshold of thermal degradation[17]. Therefore, MgRPs can be considered thermal stable during the application of powder topcoat.

\subsection{Coating Application}

The application quality of a powder coat will be affected by surface conditions of the substrate. Therefore, SEM Images of coating cross-sections were taken to assess the application quality of powder topcoat on top of MgRP. As shown in Fig. 3, powder topcoats on MgRP cover the surface of MgRP very well. No difference was observed on powder topcoats between coating systems with and without MgRP, which suggests that the application quality of powder topcoat on $\mathrm{MgRP}$ is as good as powder topcoat on $\mathrm{Al}$ alloy.

\subsection{Adhesion tests}

One of the most important properties in corrosion protective coatings is the coating adhesion to the substrate. Thus, pull-off adhesion test was conducted in this research to evaluate the adhesion strength of the (MgRP-powder topcoat) coating (Fig.4). The results show that the adhesion strength is similar between coating systems with and without MgRP. However, when

conducting the adhesion tests, coating detached between MgRP/Al interface for the coating systems with MgRP, which suggests that the adhesion strength between MgRP and powder topcoat is greater than the measurement results. This indicates that powder topcoat adheres stronger to $\mathrm{MgRP}$ than to $\mathrm{Al}$ substrate.

\subsection{EIS measurement}


EIS has been used widely in studies of corrosion prevention by organic coatings. The coating barrier properties can be determined by the change of the coating resistance. Generally, for organic coating systems, the low frequency impedance is an indication of coating barrier properties[18]. EIS results on unscribed samples (Fig. 5) show that, before exposure, all the samples have very high impedance at $0.01 \mathrm{~Hz}$, exceeding $10^{10} \mathrm{Ohm}$. The $0.01 \mathrm{~Hz}$ impedance remains the same even after 3000 hours of exposure. This indicates that all four coating systems provide excellent barrier protection to the substrate under prohesion test. In addition, the phase angle shifts for all four coating systems are constant around -90 degree over entire exposure (not shown). This suggests purely capacitive behavior of the coating systems, which again indicates that all the coating systems provide very effective barrier protection even after 3000 hours of exposure.

\subsection{Visual analysis}

Visual inspection of the scribed samples after Prohesion ${ }^{\circledR}$ exposure was conducted to evaluate the response of the four coating systems to a defect (Fig. 6-9). For Al-E coating system (Fig.6), delamination of the powder topcoat was observed around the scribe area after 600 hours of exposure. After 1500 hours of exposure, the delamination area has spread to most of the surface. The image of Al alloy substrate after removal of the powder topcoat shows that most of the Al alloy surface was corroded. For Al-Dip system (Fig.7), delamination of the powder topcoat was observed after 1100 hours of exposure, and the delamination area spread to most of the surface after 2000 hours of exposure. The image of Al alloy substrate after removal of the powder topcoat also shows that most of the Al alloy surface was corroded. In contrast, for coating systems with MgRP (Fig.8\&9), slight delamination of powder topcoat was observed around the scribed area after 2000 hours of exposure. Even after 3500 hours of exposure, the 
delamination area was still restricted to the scribed area. The images of $\mathrm{Al}$ alloy substrate after removal of the powder topcoat show that corrosion of $\mathrm{Al}$ alloy only occurred around the scribed area for both MgRP-E and MgRP-Dip coating systems. The difference between samples with and without MgRP along with the EIS measurements on unscribed samples confirms that powder coat by itself provides corrosion protection through its effective barrier property. However, once a defect developed in the coating, undercoat corrosion started and spread rapidly, because powder coat does not provide any corrosion inhibition effect. By adding MgRP as under layer, when a defect occured, undercoat corrosion can be prevented by MgRP through cathodic protection. Consequently, (MgRP-powder topcoat) coating system provided not only excellent barrier properties but also superior cathodic protection effect. The corrosion protection time of the (MgRP-powder topcoat) coating system was much longer than the powder coat by itself.

\subsection{Gloss measurement}

The appearance of a painted surface has always been an important factor, because it is often the first impression of a product seen by the end-user, especially in the automotive and consumer appliances industries[19]. For a multilayer coating system, surface properties of the under layers might influence the appearance of the final paint appearance[20]. Therefore, gloss changes of the powder topcoat were measured to evaluate the influence of MgRPs on the final paint appearance. As shown in Fig.10, the coating systems with and without MgRPs show similar gloss values before exposure. After 750 hours of exposure, a slight increase of the gloss values was observed for all four coating systems. The increase of gloss value might due to the swelling of the coatings during exposure, which reduces the roughness of the coatings caused by shrinkage during curing[21]. After 3000 hours of exposure, the gloss values started decreasing for all four coating systems due to surface erosion by weathering. The similar gloss values and the same 
trend of gloss changes for all four coating systems suggest that at least for the coating systems tested in this research, using MgRPs as an under layer does not affect the final coating appearance.

\section{Conclusions}

(1) Powder topcoat can be applied on top of MgRP through both fluidized bed and electrostatic spray methods. SEM images of cross-section of coating systems suggests that using $\mathrm{MgRP}$ as an under layer for powder topcoat doesn't undermine the application quality of powder topcoat.

(2) TGA results shows that MgRP is thermally stable during the application of powder topcoat; and adhesion tests indicate that powder topcoat adheres stronger to MgRP than to $\mathrm{Al}$ substrate.

(3) Accelerating weathering test shows that (MgRP-powder topcoat) coating system provides much longer corrosion protection time to Al substrate than the powder topcoat alone, since (MgRP-powder topcoat) coating system provided both excellent barrier properties through powder topcoat, and superior cathodic protection through MgRP.

(4) Gloss measurements indicates that for the coating systems tested in this research, using $\mathrm{MgRP}$ as an under layer does not affect the final coating appearance.

\section{Acknowledgements}

The authors would like to gratefully acknowledge US DOD, OSD, and Technical Corrosion Collaboration (TCC) for the funding of this research. Valspar Corporation is gratefully acknowledged for helpful suggestions and the supply of powder coating. Also, the authors are grateful to Scott Payne (USDA/NDSU) for the assistance in the SEM study. 


\section{References:}

[1] B.J.E. Merten, D. Battocchi, G.P. Bierwagen, Aluminum alloy 2024-T3 protection by magnesium-rich primer with chromate-free metal salts, Prog. Org. Coatings. 78 (2015) 446-454.

[2] D. Zhu, W.J. van Ooij, Corrosion protection of AA 2024-T3 by bis-[3(triethoxysilyl)propyl]tetrasulfide in neutral sodium chloride solution. Part 1: corrosion of AA 2024-T3, Corros. Sci. 45 (2003) 2163-2175.

[3] Z. Szklarska-Smialowska, Pitting corrosion of aluminum, Corros. Sci. 41 (1999) 17431767.

[4] D.E. Beving, A.M.P. McDonnell, W. Yang, Y. Yan, Corrosion resistant high-silica-zeolite MFI coating, J. Electrochem. Soc. 153 (2006) B325.

[5] J.B. Bajat, J.P. Popić, V.B. Mišković-Stanković, The influence of aluminium surface pretreatment on the corrosion stability and adhesion of powder polyester coating, Prog. Org. Coatings. 69 (2010) 316-321.

[6] R.G. Haverkamp, D.C.W. Siew, T.F. Barton, XPS study of the changes during the service life of polyester powder coatings, Surf. Interface Anal. 33 (2002) 330-334.

[7] M.E. Nanna, G.P. Bierwagen, Mg-rich coatings: A new paradigm for Cr-free corrosion protection of Al aerospace alloys, J. Coatings Technol. Res. 1 (2004) 69-80.

[8] S.S. Pathak, S.K. Mendon, M.D. Blanton, J.W. Rawlins, Magnesium-Based Sacrificial Anode Cathodic Protection Coatings (Mg-Rich Primers) for Aluminum Alloys, Metals (Basel). 2 (2012) 353-376.

[9] Y. Takeshita, T. Kamisho, S. Sakata, T. Sawada, Y. Watanuki, R. Nishio, et al., Dual layer structural thermoplastic polyester powder coating film and its weathering resistance, J. Appl. Polym. Sci. 128 (2013) 1732-1739.

[10] M. Bjordal, S.B. Axelsen, O.O. Knudsen, Quality criteria of powder coated HDG steel in corrosive environment, Prog. Org. Coatings. 56 (2006) 68-75.

[11] S. Radhakrishnan, N. Sonawane, C.R. Siju, Epoxy powder coatings containing polyaniline for enhanced corrosion protection, Prog. Org. Coatings. 64 (2009) 383-386.

[12] A. Simões, D. Battocchi, D. Tallman, G. Bierwagen, Assessment of the corrosion protection of aluminium substrates by a Mg-rich primer: EIS, SVET and SECM study, Prog. Org. Coatings. 63 (2008) 260-266.

[13] A.M. Simões, D. Battocchi, D.E. Tallman, G.P. Bierwagen, SVET and SECM imaging of cathodic protection of aluminium by a Mg-rich coating, Corros. Sci. 49 (2007) 3838-3849. 
[14] A.D. King, B. Kannan, J.R. Scully, Environmental degradation of a Mg-rich primer in selected field and laboratory environments : part 1-without a topcoat, c (2014) 512-535.

[15] J. Li, J. He, B.J. Chisholm, M. Stafslien, D. Battocchi, G.P. Bierwagen, An investigation of the effects of polymer binder compositional variables on the corrosion control of aluminum alloys using magnesium-rich primers, J. Coatings Technol. Res. 7 (2010) 757 764.

[16] Z.W. Wicks, F.N. Jones, S.P. Pappas, D.A. Wicks, Evaporation of solvents from coating films, in: Org. Coatings Sci. Technol., 3rd ed., John Wiley \& Sons, Inc., New Jersey, 2007: pp. 363-365.

[17] D. Ajloo, A. Sharifian, H. Behniafar, Prediction of thermal decomposition temperature of polymers using QSPR methods, Bull. Korean Chem. Soc. 29 (2008) 2009-2016.

[18] H. Xu, D. Battocchi, D.E. Tallman, G.P. Bierwagen, Use of magnesium alloys as pigments in magnesium-rich primers for protecting aluminum alloys, Corrosion. 65 (2009) 318-325.

[19] S. Mezghani, H. Zahouani, J.J. Piezanowski, Multiscale characterizations of painted surface appearance by continuous wavelet transform, J. Mater. Process. Technol. 211 (2011) 205-211.

[20] G. Kigle-boeckler, Surface smoothness and its influence on paintappearance . How to measure and control it ?, in: Color. Technol. Plast., William Andrew, 1999: pp. 103-111.

[21] H.J. Braun, D.P. Cobranchi., Durability and gloss, J. Coatings Technol. 67 (1995) 55-62. 


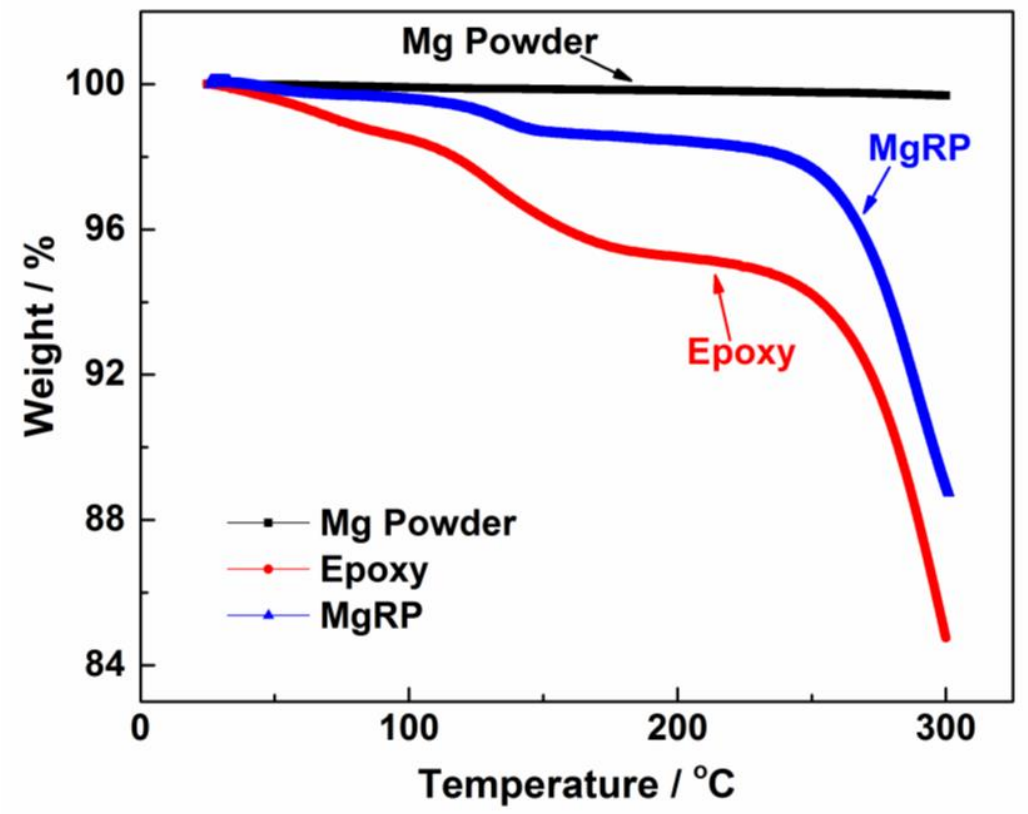

Figure 1. Thermogravimetric analysis of $\mathrm{MgRP}, \mathrm{Mg}$ pigment and epoxy primer

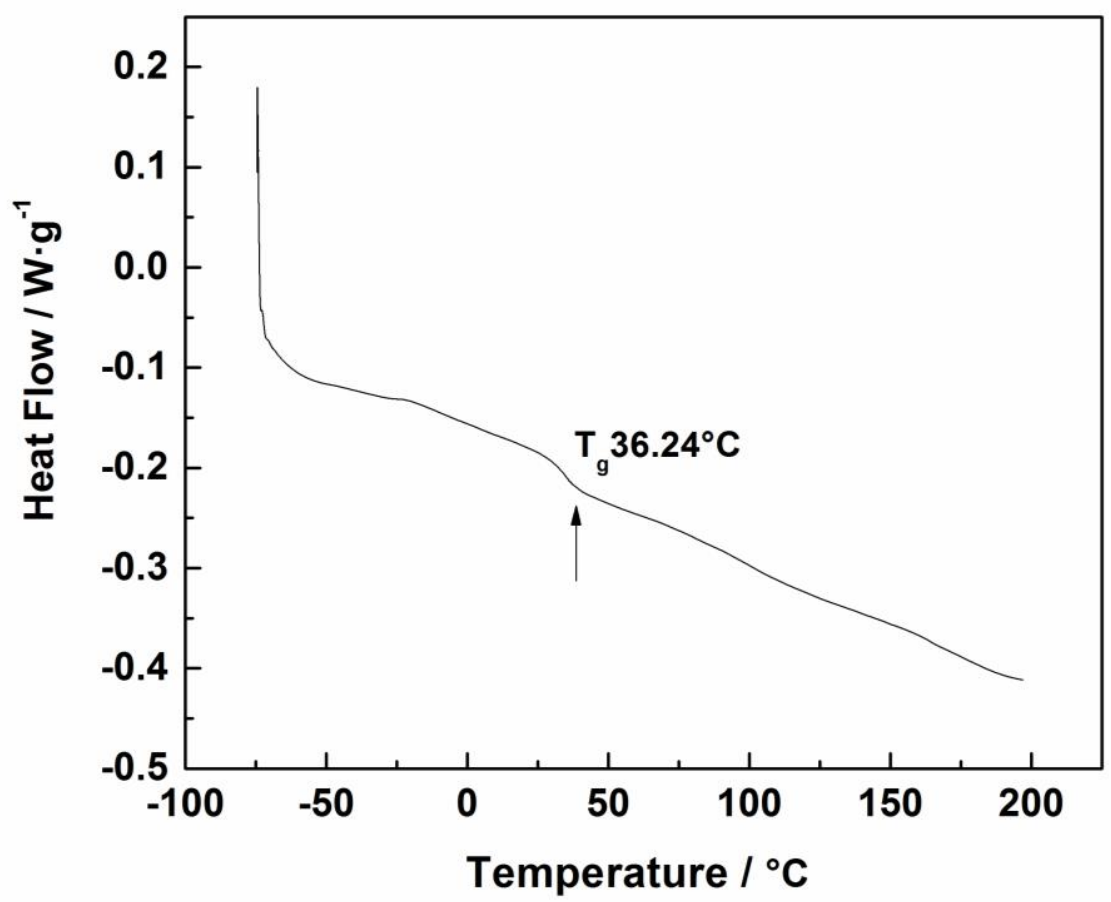

Figure 2. DSC analysis of MgRP 

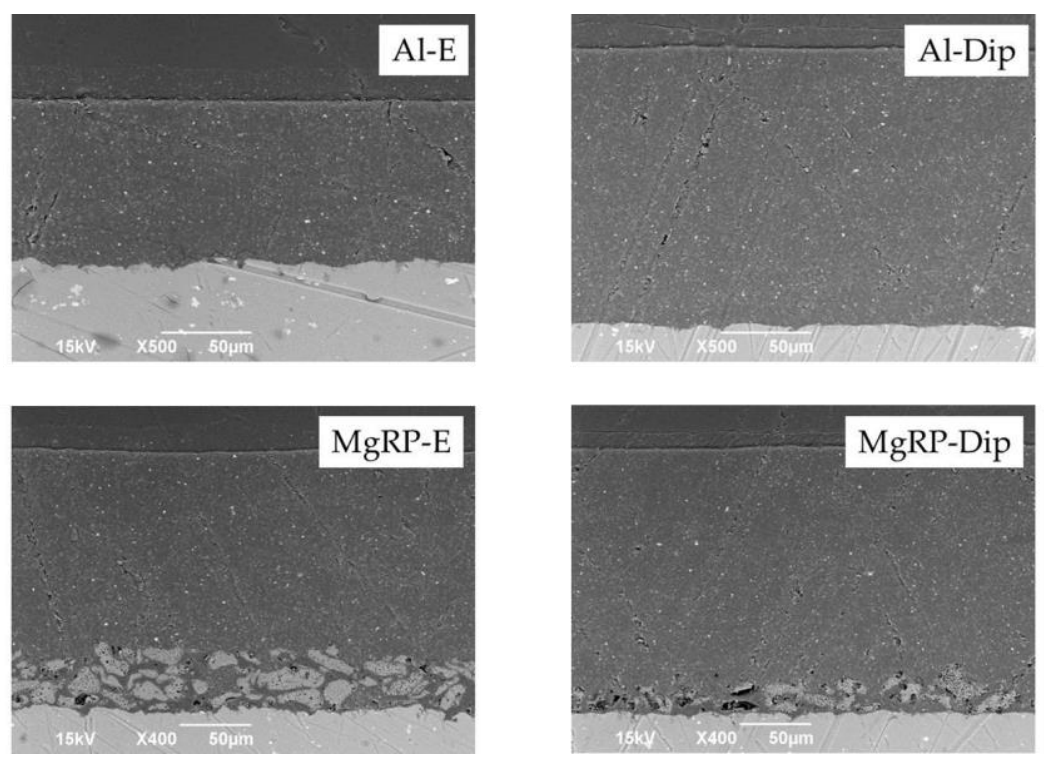

Figure 3. SEM images of four samples: Al-E, Al-D, MgRP-E and MgRP-D

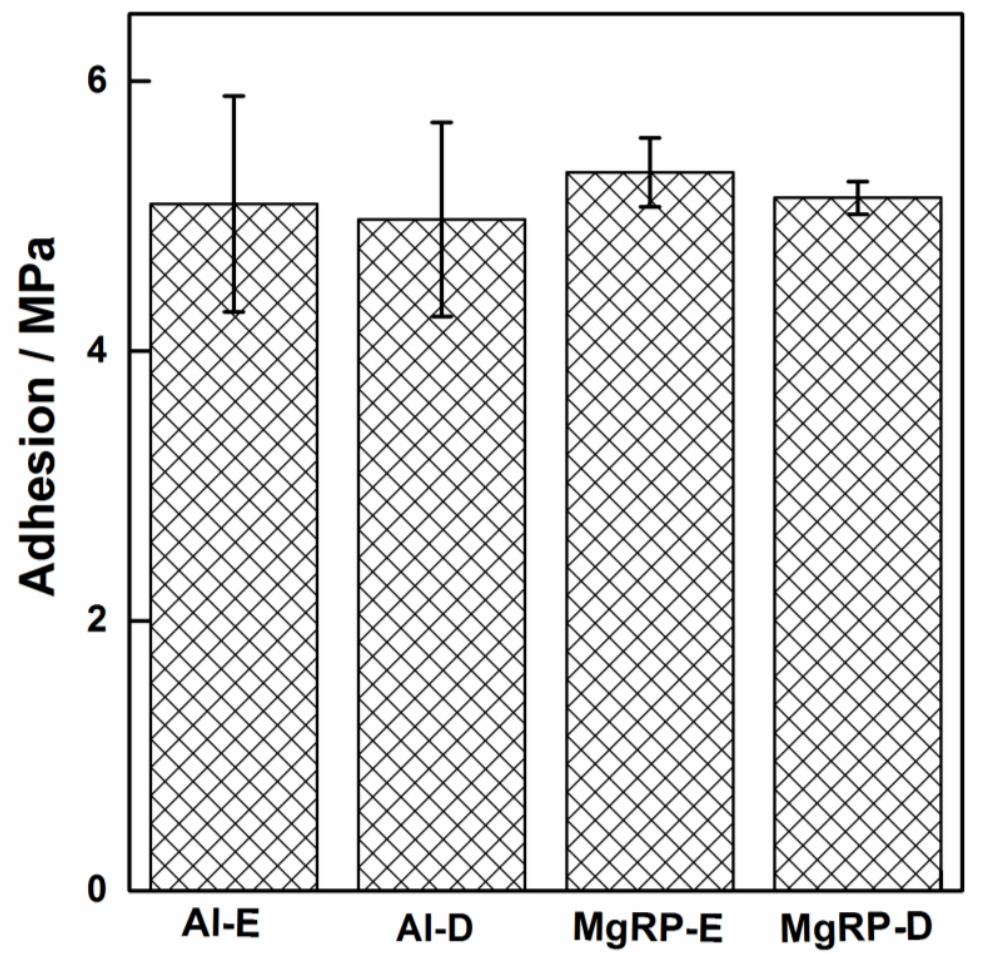

Figure 4. Adhesion strength of four samples: Al-E, Al-D, MgRP-E and MgRP-D 


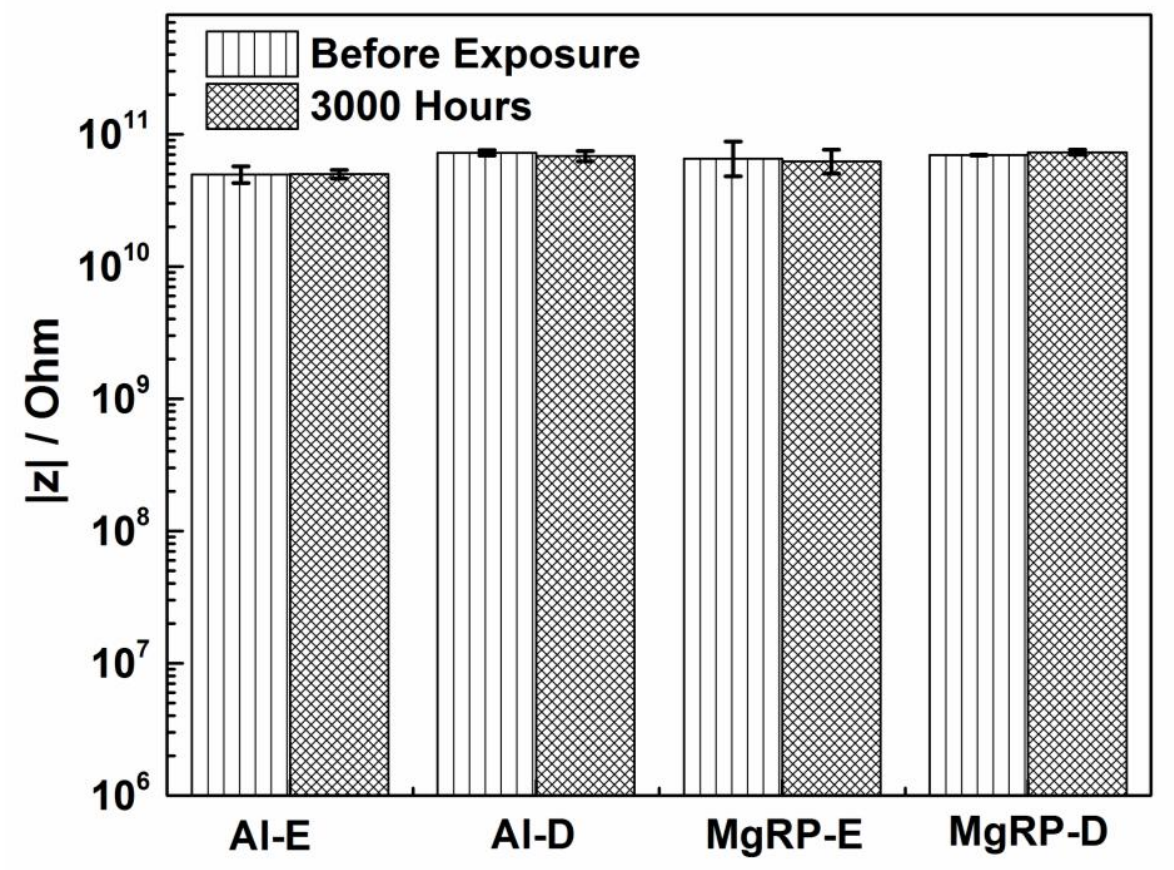

Figure 5. $\mathrm{Z}_{0.01 \mathrm{~Hz}}$ of four samples: Al-E, Al-D, MgRP-E and MgRP-D

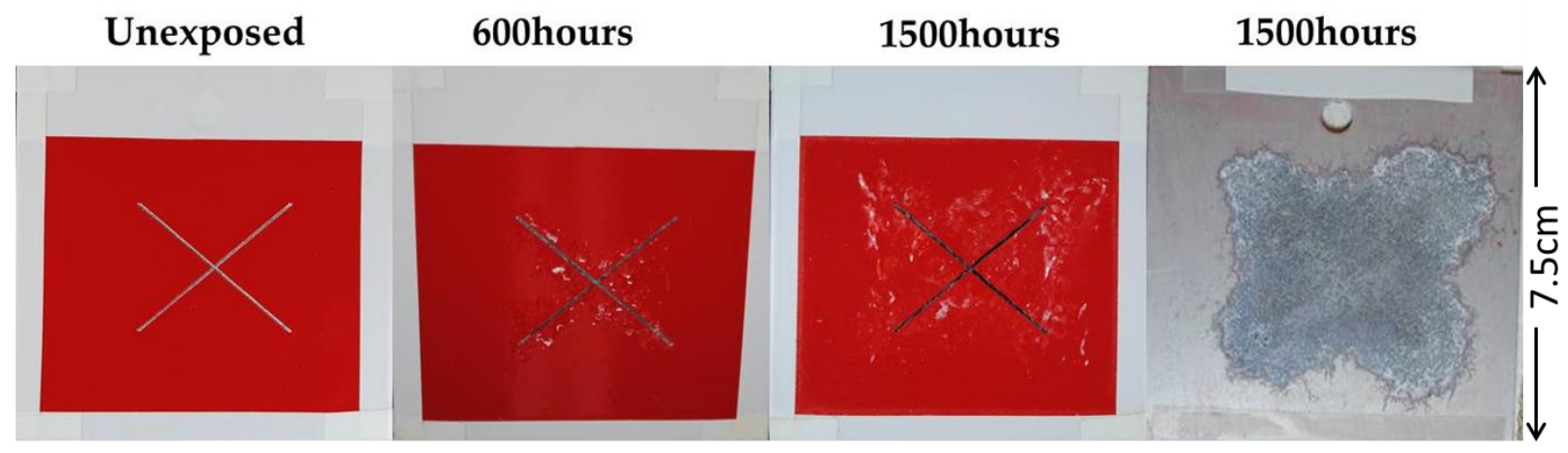

Figure 6. Images of Al-E coating system before and after prohesion exposure

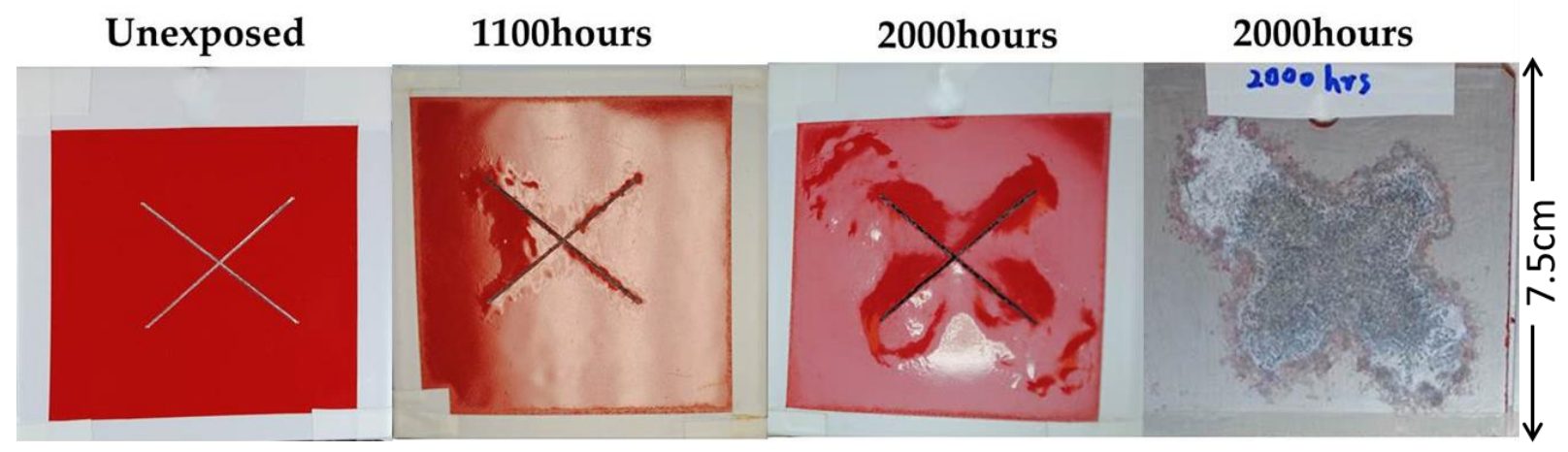

Figure 7. Images of Al-D coating system before and after prohesion exposure 


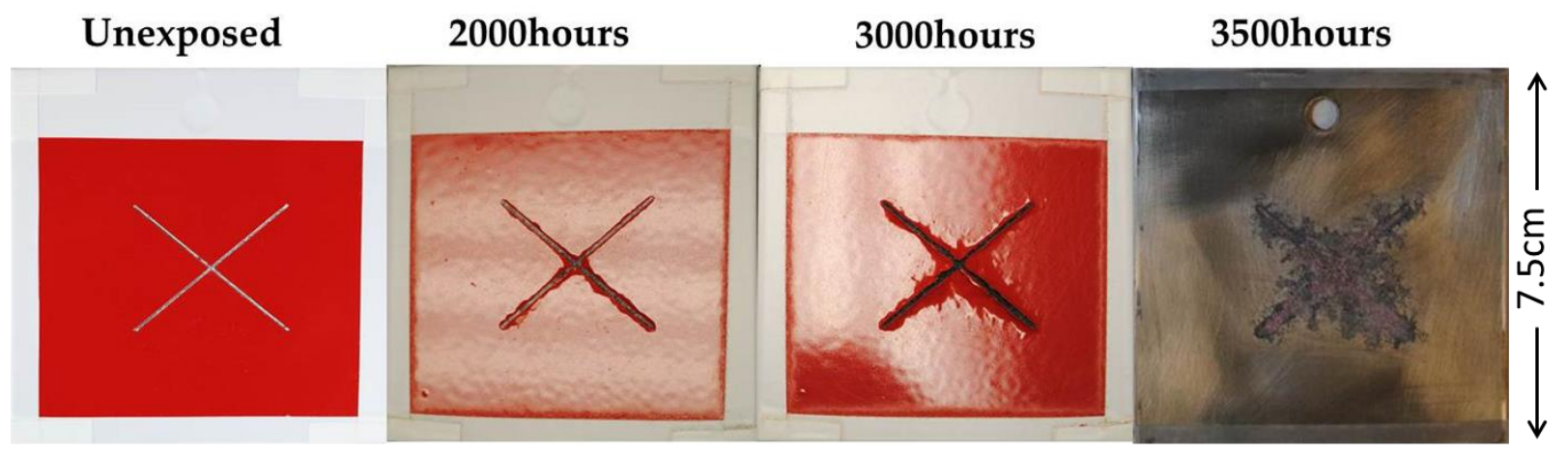

Figure 8. Images of MgRP-E coating system before and after prohesion exposure

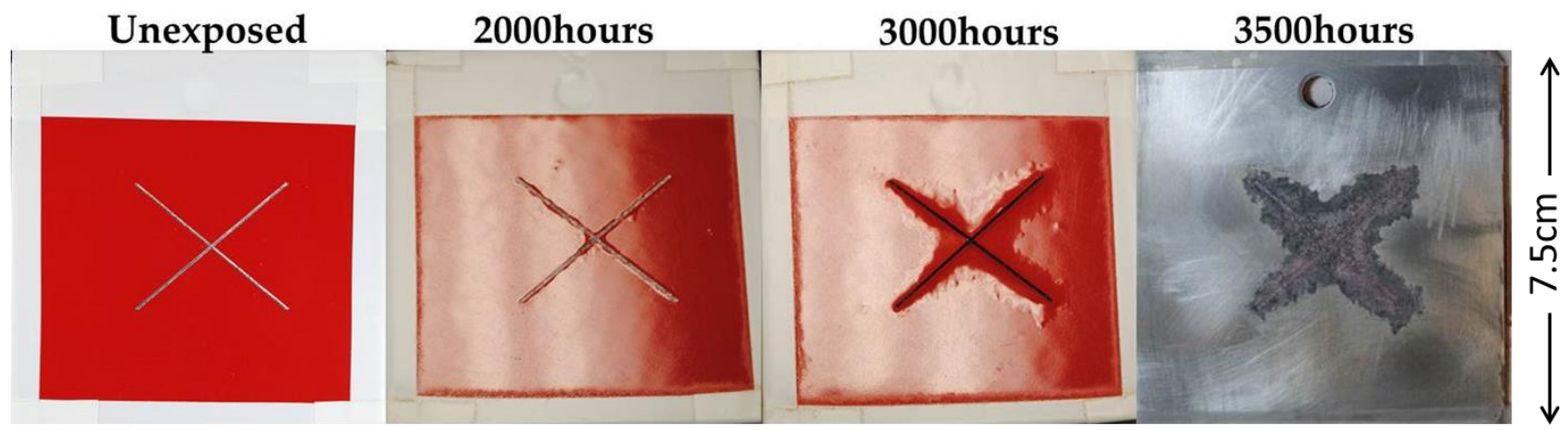

Figure 9. Images of MgRP-D coating system before and after prohesion exposure

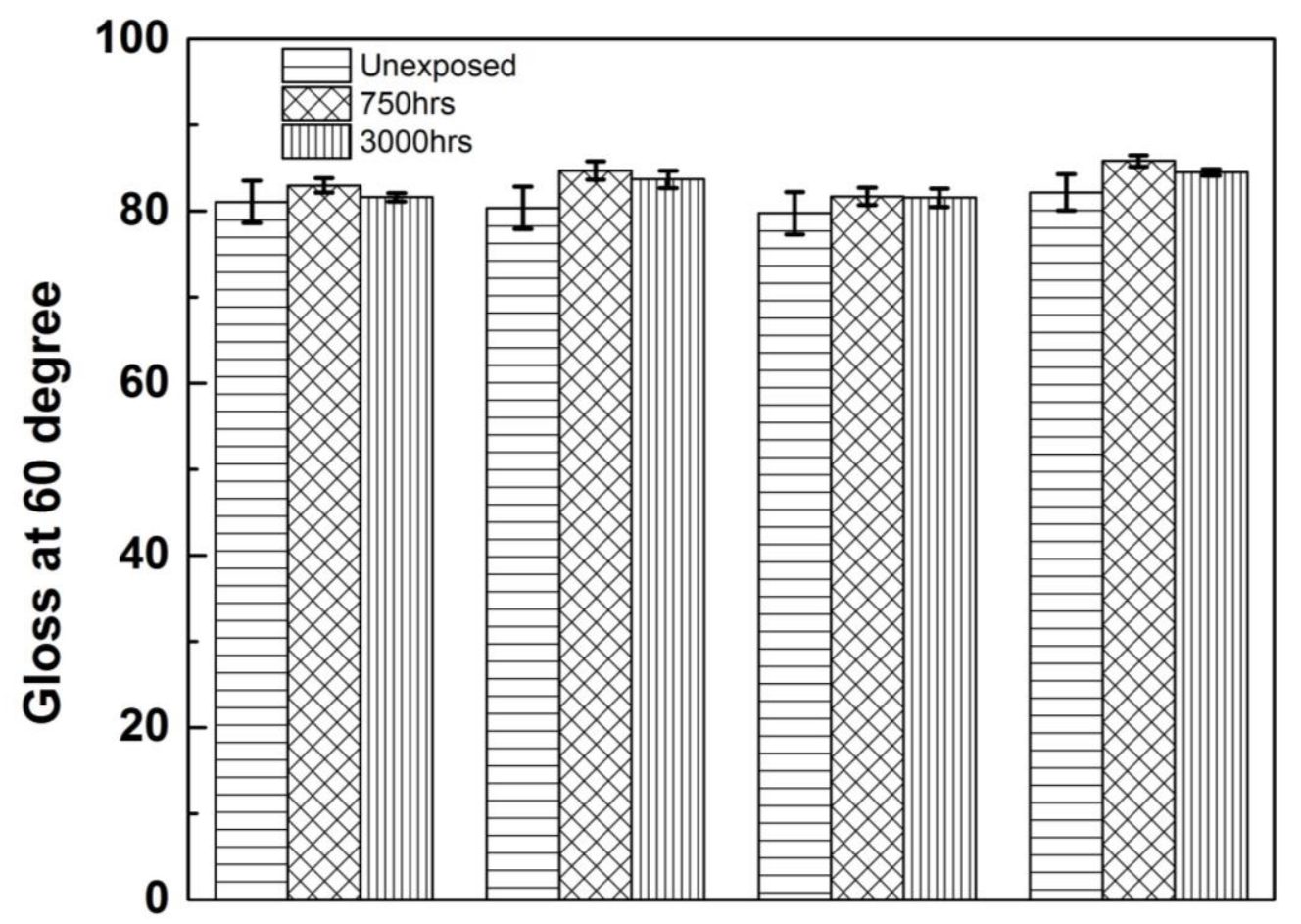

Figure 10. Gloss measurements of four coating systems before and after prohesion exposure 